NASA/CR—2006-214132

\title{
Further Refinement of the LEWICE SLD Model
}

William B. Wright

QSS Group, Inc., Cleveland, Ohio 


\section{NASA STI Program . . . in Profile}

Since its founding, NASA has been dedicated to the advancement of aeronautics and space science. The NASA Scientific and Technical Information (STI) program plays a key part in helping NASA maintain this important role.

The NASA STI Program operates under the auspices of the Agency Chief Information Officer. It collects, organizes, provides for archiving, and disseminates NASA's STI. The NASA STI program provides access to the NASA Aeronautics and Space Database and its public interface, the NASA Technical Reports Server, thus providing one of the largest collections of aeronautical and space science STI in the world. Results are published in both non-NASA channels and by NASA in the NASA STI Report Series, which includes the following report types:

- TECHNICAL PUBLICATION. Reports of completed research or a major significant phase of research that present the results of NASA programs and include extensive data or theoretical analysis. Includes compilations of significant scientific and technical data and information deemed to be of continuing reference value. NASA counterpart of peer-reviewed formal professional papers but has less stringent limitations on manuscript length and extent of graphic presentations.

- TECHNICAL MEMORANDUM. Scientific and technical findings that are preliminary or of specialized interest, e.g., quick release reports, working papers, and bibliographies that contain minimal annotation. Does not contain extensive analysis.

- CONTRACTOR REPORT. Scientific and technical findings by NASA-sponsored contractors and grantees.
- CONFERENCE PUBLICATION. Collected papers from scientific and technical conferences, symposia, seminars, or other meetings sponsored or cosponsored by NASA.

- SPECIAL PUBLICATION. Scientific, technical, or historical information from NASA programs, projects, and missions, often concerned with subjects having substantial public interest.

- TECHNICAL TRANSLATION. Englishlanguage translations of foreign scientific and technical material pertinent to NASA's mission.

Specialized services also include creating custom thesauri, building customized databases, organizing and publishing research results.

For more information about the NASA STI program, see the following:

- Access the NASA STI program home page at http://www.sti.nasa.gov

- E-mail your question via the Internet to help@sti.nasa.gov

- Fax your question to the NASA STI Help Desk at 301-621-0134

- Telephone the NASA STI Help Desk at 301-621-0390

- Write to:

NASA STI Help Desk

NASA Center for AeroSpace Information 7121 Standard Drive Hanover, MD 21076-1320 
NASA/CR—2006-214132

AIAA-2006-0464

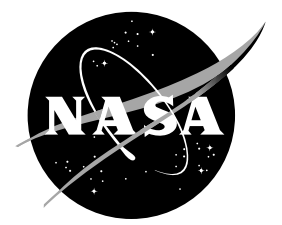

\section{Further Refinement of the LEWICE SLD Model}

William B. Wright

QSS Group, Inc., Cleveland, Ohio

Prepared for the

44th Aerospace Sciences Meeting and Exhibit

sponsored by the American Institute of Aeronautics and Astronautics

Reno, Nevada, January 9-12, 2006

National Aeronautics and

Space Administration

Glenn Research Center

Cleveland, Ohio 44135 


\section{Acknowledgments}

The author would like to acknowledge Colin Bidwell, Mark Potapczuk, and Dean Miller, NASA Glenn Icing Branch, as well as Paul Tsao and David Anderson, Ohio Aerospace Institute, for their insight and experience with SLD issues. He would also like to acknowledge Colin Bidwell and Mike Papadakis for insights into the experimental database that they had collected and Aaron Armstrong and Timothy Mosig for their assistance with validation tasks. The author would also like to acknowledge the continued financial support from NASA Glenn Research Center for this research.

This report is a formal draft or working paper, intended to solicit comments and ideas from a technical peer group.

This report contains preliminary findings, subject to revision as analysis proceeds.

Trade names and trademarks are used in this report for identification only. Their usage does not constitute an official endorsement, either expressed or implied, by the National Aeronautics and Space Administration.

Level of Review: This material has been technically reviewed by technical management.

Available from

NASA Center for Aerospace Information 7121 Standard Drive

Hanover, MD 21076-1320
National Technical Information Service 5285 Port Royal Road Springfield, VA 22161 


\title{
Further Refinement of the LEWICE SLD Model
}

\author{
William B. Wright \\ QSS Group, Inc. \\ Cleveland, Ohio 44135
}

\begin{abstract}
A research project is underway at NASA Glenn Research Center to produce computer software that can accurately predict ice growth for any meteorological conditions for any aircraft surface. This report will present results from version 3.2 of this software, which is called LEWICE. This version differs from previous releases in that it incorporates additional thermal analysis capabilities, a pneumatic boot model, interfaces to external computational fluid dynamics (CFD) flow solvers and has an empirical model for the supercooled large droplet (SLD) regime. An extensive comparison against the database of ice shapes and collection efficiencies that have been generated in the NASA Glenn Icing Research Tunnel (IRT) has also been performed. The complete set of data used for this comparison will eventually be available in a contractor report. This paper will show the differences in collection efficiency and ice shape between LEWICE 3.2 and experimental data. This report will first describe the LEWICE 3.2 SLD model. A semiempirical approach was used to incorporate first order physical effects of large droplet phenomena into icing software. Comparisons are then made to every two-dimensional case in the water collection database and the ice shape database. Each collection efficiency condition was run using the following four assumptions: 1) potential flow, no splashing; 2) potential flow, with splashing; 3) Naviér-Stokes, no splashing; 4) Naviér-Stokes, with splashing. All cases were run with 21 bin drop size distributions and a lift correction (angle of attack adjustment). Quantitative comparisons are shown for impingement limit, maximum water catch, and total collection efficiency. Due to the large number of ice shape cases, comprehensive comparisons were limited to potential flow cases with and without splashing. Quantitative comparisons are shown for horn height, horn angle, icing limit, area, and leading edge thickness. The results show that the predicted results for both ice shape and water collection are within the accuracy limits of the experimental data for the majority of cases.
\end{abstract}

\section{Nomenclature}

$\begin{array}{ll}A_{p} & \text { cross-sectional area of particle }\left(\mathrm{m}^{2}\right) \\ c & \text { chord }(\mathrm{m}) \\ D & \text { drag force }\left(\mathrm{kg} * \mathrm{~m} / \mathrm{s}^{2}\right) \\ D_{l e} & \text { Airfoil leading edge diameter }(\mathrm{m}) \\ d & \text { particle diameter }(\mathrm{m}) \\ E & \text { total water collection efficiency (dimensionless) } \\ f & \text { drop frequency }(\mathrm{Hz}) \\ g & \text { gravitational constant }=9.8 \mathrm{~m} / \mathrm{s}^{2} \\ h & \text { film thickness }(\mathrm{m}) \\ L & \text { lifting force }\left(\mathrm{kg} * \mathrm{~m} / \mathrm{s}^{2}\right) \\ \text { LWC } & \text { liquid water content }\left(\mathrm{g} / \mathrm{m}^{3}\right) \\ m & \text { particle mass }(\mathrm{kg}) \\ \dot{m} & \text { water mass flux }\left(\mathrm{kg} / \mathrm{m}^{2} \mathrm{~s}\right) \\ s & \text { surface wrap distance }(\mathrm{m}) \\ s_{l} & \text { lower impingement limit by wrap distance }(\mathrm{m}) \\ s_{l l 0} & \text { lower limit by wrap distance where } \beta=10 \text { percent }(\mathrm{m}) \\ s_{u} & \text { upper impingement limit by wrap distance }(\mathrm{m})\end{array}$






\section{A. Dimensionless Numbers}

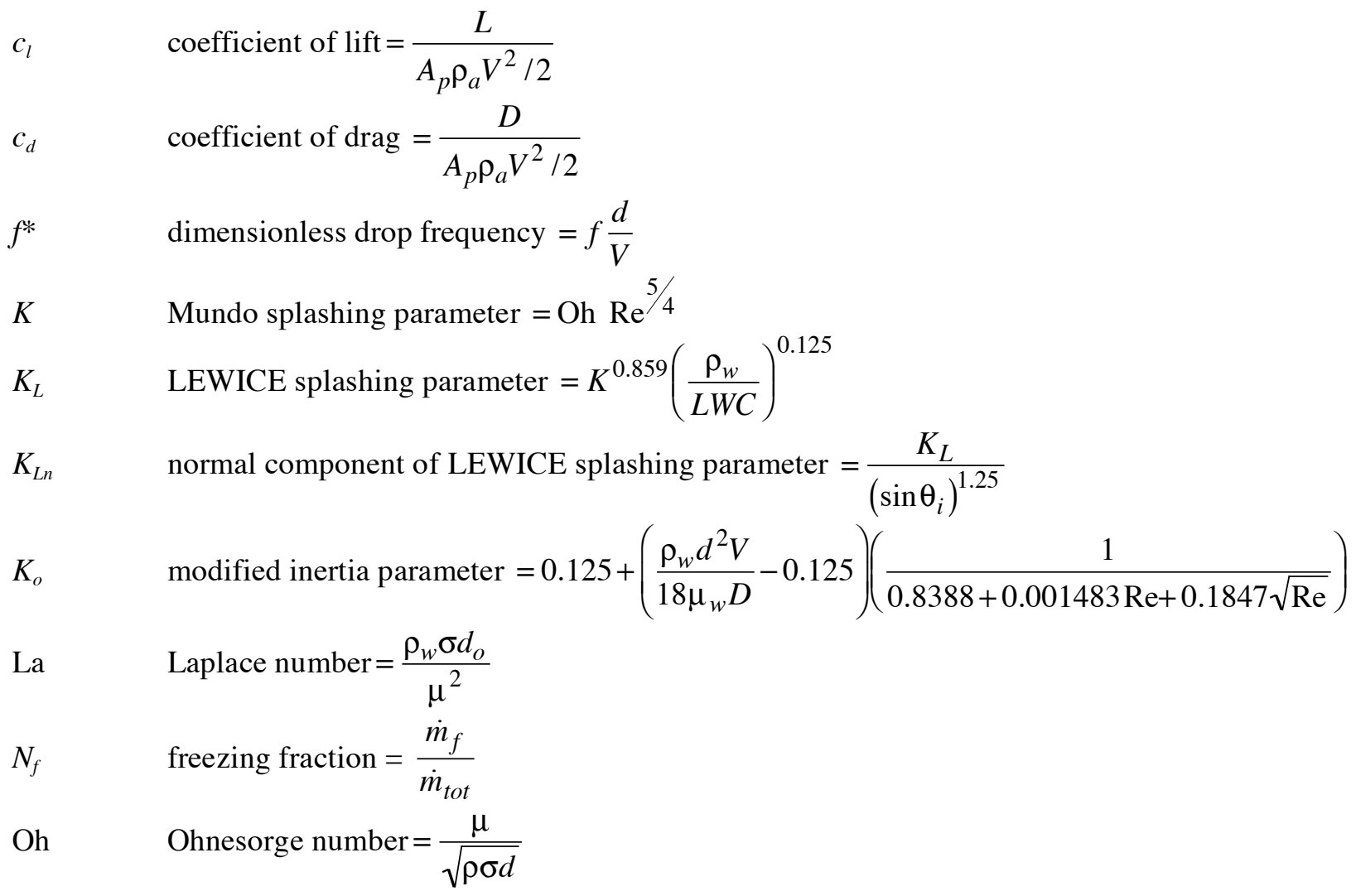




$$
\begin{aligned}
& \text { Re } \quad \text { Reynolds number }=\frac{\rho V d}{\mu} \\
& \text { We } \quad \text { Weber number }=\frac{\rho V^{2} d}{\sigma}
\end{aligned}
$$

\section{B. Greek Letters}

$\begin{array}{ll}\alpha & \text { angle of attack (degrees) } \\ \beta & \text { collection efficiency (dimensionless) } \\ \gamma & \text { angle difference between particle velocity vector and airflow velocity vector (radians) } \\ \delta & \text { film thickness (dimensionless }=h / d) \\ \mu & \text { viscosity }\left(\mathrm{kg} / \mathrm{m}^{*} \mathrm{~s}\right) \\ v & \text { kinematic viscosity of air }\left(\mathrm{m}^{2} / \mathrm{s}\right) \\ \rho & \text { density }\left(\mathrm{kg} / \mathrm{m}^{3}\right) \\ \sigma & \text { surface tension }\left(\mathrm{kg} / \mathrm{s}^{2}\right) \\ \theta & \text { impact angle (degrees) }\end{array}$

$\begin{array}{ll}\text { C. } & \text { Subscripts } \\ a & \text { air } \\ b & \text { bouncing } \\ f & \text { freezing } \\ l e & \text { leading edge } \\ \max & \text { maximum value } \\ n & \text { normal direction } \\ o & \text { initial value } \\ p & \text { particle } \\ s & \text { splashed (or secondary) drop value } \\ t & \text { tangential direction } \\ \text { term } & \text { terminal } \\ \text { tot } & \text { total } \\ w & \text { water } \\ x & x \text {-dependent } \\ y & y \text {-dependent } \\ \infty & \text { free-stream property }\end{array}$

\section{Introduction}

In 1994, an ATR-72 crashed in Roselawn, Indiana (ref. 1). It has been speculated that accident occurred due to the accumulation of ice aft of the deicing boots. Ice formed aft of the boots due to impingement of drops greater than $40 \mu \mathrm{m}$. Since then, several experimental efforts have been made to document supercooled large droplet (SLD) ice shapes and to investigate the underlying physics (refs. 2 to 7). Based on this experimental work, an empirical model was developed to account for large droplet effects in LEWICE (ref. 8).

This report will address the validation of that model against a database of water collection efficiency and ice shape data (refs. 9 to 11). This validation effort mirrors a similar effort undertaken previously for the validation of LEWICE for ice shapes (ref. 12). That report quantified the ice accretion prediction capabilities of the LEWICE 2.0 software. Several ice geometry features were proposed for comparing ice shapes in a quantitative manner. The resulting analysis showed that LEWICE 2.0 compared well to the available experimental data. The purpose of this report is to repeat the validation process using the current model with the larger databases now available. 
The report is divided into four sections. The first section will provide a description of the LEWICE software and the Naviér-Stokes flow solver WIND (ref. 13) that was used for this effort. The second section will provide a description of the LEWICE collection efficiency model with emphasis on breakup and impact physics. It will also describe the modified equations including analysis and observations from tests performed in the NASA icing research tunnel (IRT). The third section will describe the experimental data and the parameters used for quantifying the comparisons. The last section will provide validation results along with a statistical comparison of those parameters with the available experimental data.

\section{Computational Tools}

\section{A. LEWICE}

The computer program, LEWICE, embodies an analytical ice accretion model that evaluates the thermodynamics of the freezing process that occur when supercooled droplets impinge on a body. The atmospheric parameters of temperature, pressure, and velocity, and the meteorological parameters of liquid water content (LWC), droplet diameter, and relative humidity are specified and used to determine the shape of the ice accretion. The surface of the clean (un-iced) geometry is defined by segments joining a set of discrete body coordinates. The software consists of four major modules. They are 1) the flow field calculation, 2) the particle trajectory and impingement calculation, 3) the thermodynamic and ice growth calculation, and 4) the modification of the current geometry by addition of the ice growth.

LEWICE applies a time-stepping procedure to "grow" the ice accretion. Initially, the flow field and droplet impingement characteristics are determined for the clean geometry. The ice growth rate on each segment defining the surface is then determined by applying the thermodynamic model. When a time increment is specified, this growth rate can be transformed into an ice thickness and the body coordinates are adjusted to account for the accreted ice. This procedure is repeated, beginning with the calculation of the flow field about the iced geometry, then continued until the desired icing time has been reached. The results shown in this report are from version 3.2 of LEWICE (ref. 14).

\section{B. WIND}

WIND is a structured, multi-zone, compressible flow solver with flexible chemistry and turbulence models. Zonal interfaces may be abutting or overlapped, allowing the flexibility to treat complex systems moving relative to one another. WIND is a computational platform that may be used to numerically solve various sets of equations governing physical phenomena. Currently, the software supports the solution of the three-dimensional Euler and Navier-Stokes equations of fluid mechanics, along with supporting equation sets governing turbulent and chemically-reacting flows.

WIND is a product of the NPARC Alliance, a partnership between the NASA Glenn Research Center (GRC) and the Arnold Engineering Development Center (AEDC) dedicated to the establishment of a national, applications-oriented flow simulation capability. The Boeing Company has also been closely associated with the Alliance since its inception, and represents the interests of the NPARC User's Association.

\section{ICEG2D}

ICEG2D (ref. 15) is an automated grid generation program and scripting interface. The grid generation capability contains algorithms for producing single block " $\mathrm{C}$ " grids. The scripting portion of the software provides an interface between LEWICE and WIND. Flow field information from WIND is processed through the WIND utility GMAN and formatted for use in LEWICE. LEWICE then sends the completed ice shape back to ICEG2D for the next icing time step. 


\section{Collection Efficiency Physics}

Collection efficiencies are calculated in LEWICE through the use of a particle trajectory analysis. Droplets are released from a point in the freestream flow and tracked through the flow field using the following equations:

$$
m \ddot{x}_{p}=-D \cos \gamma-L \sin \gamma
$$

$$
m \ddot{y}_{p}=-D \sin \gamma+L \cos \gamma-m g
$$

where $\gamma=a \tan \frac{\dot{y}_{p}-V_{y}}{\dot{x}_{p}-V_{x}}, \quad D=c_{d} \frac{\rho_{a} V^{2}}{2} A_{p}, \quad L=c_{l} \frac{\rho_{a} V^{2}}{2} A_{p}, \quad V=\sqrt{\left(\dot{x}_{p}-V_{x}\right)^{2}+\left(\dot{y}_{p}-V_{y}\right)^{2}}$

The initial release point in the $x$-direction is determined by finding an $x$-location where all of the velocities in a vertical sweep are within 0.1 percent of the freestream value. The initial release point in the $y$-direction is determined from the angle of attack. The initial velocity is assumed to be the terminal droplet velocity, which is given by

where

$$
\begin{gathered}
c_{d} \operatorname{Re}_{\text {term }}^{2}=\frac{4 g d\left(\rho_{w}-\rho_{a}\right)}{3 v_{a}^{2} \rho_{a}} \\
\operatorname{Re}_{\text {term }}=\frac{V_{\text {term }} d}{v_{a}}
\end{gathered}
$$

Each droplet is then tracked until it either hits the airfoil or reaches the trailing edge. After the first trajectory ends, the next particle is released from a higher or lower starting point in an attempt to hit the surface. This process is continued until there exists at least one drop that passes above the airfoil and one that passes below.

Impingement limits are then found using a standard bisection search algorithm. Using the coarse limits found in the prior step, LEWICE starts a drop halfway between these limits. Based upon the end result of that trajectory, the next drop is released halfway between the current starting point and the starting point of either the upper or lower coarse limit. The coarse limit is then refined based upon the trajectory results. This process is repeated until the starting point of a drop that hits the airfoil and the starting location of a drop that misses the airfoil is within $10^{-5}$ (dimensionless) The bisection is then repeated to find the second impingement limit.

Collection efficiency is then determined by sending a user-determined number of trajectories uniformly spaced between the impingement limit starting locations. The starting and ending locations of these trajectories are stored. Collection efficiency is then calculated by the following definition:

$$
\beta \equiv \frac{d y_{o}}{d s}
$$

\section{A. Literature review}

A previous report published a literature review of large droplet physics (ref. 8). In that report, the additional physics that were found to be of most importance were drop breakup and drop splashing. While many of the other physical effects can be studied, this report will focus on those that have the most impact on collection efficiency. 


\section{Drop Breakup}

If a large drop moves at a high enough velocity, it can break up due to shear. Breakup occurs when the drop passes a critical Weber number. Values for this critical Weber number vary widely in the literature.

The Weber number is given by:

$$
\mathrm{We}_{p}=\frac{\rho_{a} V^{2} d}{\sigma}
$$

For water drops falling at their terminal velocity, the critical Weber number (based on air density) is approximately 10. For water drops accelerated by a shock wave, a value of 6.5 is given. Krzeczkowski (ref. 19) and Hsiang (ref. 20) each measured droplet breakup for shear-induced flows and reported values ranging from 10 to 20 . Ibrahim et al. (ref. 21) provided a more detailed analysis of the droplet deformation and breakup using a Taylor analogy model. The Weber number of each trajectory was output from LEWICE for the case described above to investigate this effect.

An empirical relationship found in Hsiang and Faeth (ref. 20) was added to LEWICE in order to estimate the reduction of collection efficiency due to breakup. In their model, droplets will start to break up when the critical Weber number is greater than 13. This Weber number is based on the air density as defined earlier in this report. Since droplet breakup occurs rapidly compared to the trajectory time step, breakup is considered to be instantaneous. Dai and Faeth (ref. 22) produced some excellent photographs of the breakup process using pulsed shadowgraphy and holography.

Secondary particle size is given by the following equation:

$$
\begin{gathered}
d_{s}=6.2\left(\frac{\rho_{w}}{\rho_{a}}\right)^{1 / 4} \operatorname{Re}_{w}{ }^{-1 / 2} d_{o} \\
\text { where } \operatorname{Re}_{w}=\frac{\rho_{w} V d}{\mu_{w}}
\end{gathered}
$$

This correlation can be applied to an Eulerian system as well as the Lagrangian tracking system used by LEWICE. However, it would be necessary in an Eulerian system to solve coupled sets of equations for each drop size generated. In the Lagrangian system, the smaller drop size is simply tracked from the breakup location. An empirical relationship was chosen to assess the importance of breakup to the collection efficiency. If breakup is not important then there is no need to implement the more complicated droplet deformation and breakup (DDB) model described by Ibrahim (ref. 21).

\section{Drop Splashing}

The literature search performed for this report confirms that the primary assumption used by LEWICE 2.0 that was invalidated for SLD was the assumption that all drops that strike the surface impinge, thus neglecting splashing and/or bouncing of drops. One of the earliest detailed experimental studies was performed by Stow and Hadfield (ref. 23) who reported on the impact of water drops on a dry surface. Macklin and Metaxas (ref. 24) reported a similar study that also used ethanol and glycerol to study the effect of different fluid properties. Jayarante and Mason (ref. 25) looked at bouncing and splashing of raindrops impinging at various angles on dry surfaces and films. Wright (ref. 26) developed a theoretical splash model for raindrops for the purpose of modeling soil erosion.

Harlow and Shannon (ref. 27) solved the Naviér-Stokes equations for the impact of a single drop on a dry surface or film. A more recent work was performed by Yarin and Weiss (refs. 28 and 29) who proposed a splashing model as a type of kinematic discontinuity. Other works include Rein (ref. 30) who provides a review of several papers, including phenomena such as bouncing along with splashing and 
coalescence, and Chandra and Avedisian (ref. 31) who documented photographically the droplet structure during the deformation process.

Computationally, a detailed physical model of droplet splashing would require solving the NaviérStokes equations for each droplet impact using a Volume of Fluid (VOF) model such as that described by Hirt (ref. 32). Examples of this type of calculation were reported by Trapeaga and Szekely (ref. 33) as well as Tan and Papadakis (ref. 2). Current computational capabilities usually limit this approach to single drop calculations. In a typical icing encounter, thousands of droplet impacts are recorded per second, making this type of analysis prohibitively expensive. An empirical or semi-empirical approach is therefore necessary.

Experimental studies by Mundo, Sommerfeld, and Tropea (refs. 34 to 36) examined droplet-wall collisions and correlate splashing in terms of Reynolds number and Ohnesorge number:

$$
\mathrm{Oh}=\frac{\sqrt{\mathrm{We}}}{\operatorname{Re}}=\frac{\mu}{\sqrt{\rho \sigma d}}
$$

The Reynolds and Ohnesorge numbers are based on the liquid (water) properties and the component of the impact velocity normal to the surface. Based on the results of their experiment, splashing occurs if the factor $K=\mathrm{Oh} * \mathrm{Re}^{1.25}$ is greater than 57.7.

The Mundo papers also provide a characterization of the size, velocity, and direction of the splashed particles. Their later references provide an empirical splashing model that can be used in Lagrangian tracking schemes. The empirical formulas calculate splashed drop size, splash velocity, splash angle, and deposited mass as functions of the incoming parameters. In last year's report, several problems were noted with the empirical relationships developed at low speeds $(<30 \mathrm{~m} / \mathrm{s})$. The following section provides a summary of the current splashing model.

3. Summary of LEWICE Splashing Model

The parameters needed for an empirical splashing model are the splashing threshold, the splashed drop size (or drop size distribution), the splashed velocity (or a distribution of splash velocities), the splash angle (or a distribution of splash angles), and the amount of splashed mass. The number of splashed particles is needed only if all splashed particles are to be tracked. The models presented in the literature typically provide these variables as a ratio to the incoming parameters.

The droplet experiments mentioned previously were developed using similar experimental techniques and therefore had similar ranges of applicability. The upper limit on drop size and velocity were $340 \mu \mathrm{m}$ and $30 \mathrm{~m} / \mathrm{s}$ respectively. Droplet frequency and film thicknesses were in the range expected for icing encounters except at the lower range. Splash data exists for dry surfaces $(\delta=0)$ and for film thicknesses of $0.3<\delta<3$. The applicability of these models to very thin films is unknown. Similarly, droplet frequencies are lower in the SLD range due to the lower water contents as well as the higher drop sizes. However, the correlations are well behaved in these limits and tend toward limiting values.

Previous reports used a modified version of empirical relationships reported by Trujillo et al. (ref. 38). In addition, a bouncing model was incorporated into LEWICE based on physical arguments that since droplet impact phenomena at the high velocities encountered in aircraft icing have not previously been studied in the literature, it is reasonable to assume that additional phenomena could be present at these velocities. In the current model, both effects were combined into a single correlation. The correlation was determined by matching the collection efficiency results to the experimental collection efficiency database. All 114 cases in this database were used to produce this calibration. This process was made possible through the use of a Visual Basic script that ran the cases and made collection efficiency charts in Excel for all 114 runs. The procedure used was to run all the cases in batch mode and then compare the collection efficiencies for all of the runs. The splashing correlation was then adjusted to match the largest number of cases possible. Grid-independent solutions of the Naviér-Stokes equation were generated using WIND and then used for the flow solution inputs. Because the airfoil shape does not change during the impingement tests, the flow solutions need only be generated once. Since the collection 
efficiency database was run at one airspeed $(175 \mathrm{mph})$, several runs were also performed at higher speeds and at larger drop sizes in order to assess trends. The correlations that best matched the collection efficiency database can be expressed by:

Splashing threshold:

$$
K_{L, n}>200
$$

where

$$
\begin{gathered}
K_{L, n}=\sqrt{K} f^{*-3 / 8} \\
\frac{d_{s}}{d_{o}}=8.72 e^{-0.0281 K}, 0.05 \leq \frac{d_{s}}{d_{o}} \leq 1 ; \quad \frac{m_{s}}{m_{o}}=0.7\left[1-\sin \theta_{o}\right]\left[1-\exp \left(-0.0092 *\left(K_{L, n}-200\right)\right)\right] \\
\frac{V_{t, s}}{V_{t, o}}=1.075-0.0025 \theta_{o} ; \quad \frac{V_{n, s}}{V_{n, o}}=0.3-0.002 \theta_{o}
\end{gathered}
$$

It should be noted that if droplets impinge perpendicular to the surface $\left(\theta_{0}=90^{\circ}\right)$ then no splashing can occur. While this result is the opposite trend of the low velocity experiments, a large number of SLD cases show very little mass loss at the leading edge. Mass loss in the collection efficiency data occurs primarily at the low impact angles near the impingement limits except for the MVD $=92 \mu \mathrm{m}$ and to a lesser extent the MVD $=79 \mu \mathrm{m}$ data. A feature was added to LEWICE to track the trajectories of the splashed particles and the trajectories of particles after breakup. This process was described in a report by Rutkowski et al. (ref. 7). Mass losses due to splashing and subsequent re-impingement are also calculated. Since it is necessary to extrapolate from the experimental data for icing encounters, care must be taken, especially in high velocity impacts. The equations provided above indicate that droplet velocity (which is related to airspeed) is at least as important to the splashing process as drop size. The next section will describe the experimental data in more detail.

\section{Experimental Data}

\section{A. Collection Efficiency Data}

The experimental data used for this comparison was taken from several tests performed in the IRT (refs. 9 to 11). The tests were performed by personnel from Wichita State University, NASA, and Boeing using a spray system designed for short duration sprays. The water spray contains a known concentration of blue dye and the models are covered with a heavy weight blotter paper. The amount of dye was then measured via reflectance spectroscopy using a CCD camera. Collection efficiencies were determined on 11 different clean airfoils and 7 different iced airfoils. Drop size distributions from MVDs of 11 to $236 \mu \mathrm{m}$ were used and angle of attack was varied from $0^{\circ}$ to $8^{\circ}$.

The database consists of a wide variety of airfoils that were selected to provide a broad range of airfoil types for validation purposes. A previous report (ref. 8) contained a summary of the conditions and airfoils used in the collection efficiency tests. The drop size distributions were measured during the experiment and were modeled in LEWICE using 27-bin distributions. The estimated experimental repeatability for this data ranged from 10 to 30 percent for the older data sets. An uncertainty analysis presented in the reports on the experimental data showed that uncertainty in spray time, dye concentration, spray pressures, tunnel velocity, and cloud unsteadiness due to turbulence accounted for a 14 percent variation in maximum collection efficiency values. In the following comparison with predicted results, the 14 percent value was used as representative of the experimental error for all parameters. Specific variability of individual parameters could not be defined (ref. 39). 


\section{B. Ice Shape Data}

The experimental data described in this paper are the result of a wide variety of tests performed in the NASA Glenn Icing Research Tunnel (IRT) in recent years (refs. 17 to 24). Eight airfoils and a cylinder were selected for this comparison. These airfoils and the accompanying ice shapes represent the complete set of publicly available data that has been generated in the IRT and digitized for single element airfoils. There are a total of 2146 IRT runs analyzed for this validation report, of which 460 are repeats of previous runs in the IRT. There are 865 digitized tracings at off-centerline locations for a total of 3011 experimental ice shapes. This value is nearly triple the number of ice shapes from the previous validation. There are 741 cases with an MVD greater than $40 \mu \mathrm{m}$. Of these cases, 111 are rime or roughness (short duration) conditions and 59 cases use SLD conditions for only part of the run. The eight airfoils are as follows: a modified NACA23014, a Large Transport Horizontal Stabilizer (LTHS), a GLC305 business jet airfoil, a NACA0012, a modified NACA4415, a NACA 0015, a NACA23012, and a NLF00414 laminar flow general aviation wing. These models were described in an earlier report on the LEWICE 2.0 validation effort (ref. 12).

The data is taken in the IRT by cutting out a small section of the ice growth and tracing the contour of the ice shape onto a cardboard template with a pencil. The pencil tracing is then transformed into digital coordinates using a stylus on a digitizing table. A flat-bed scanner with digitizing software has been available to accelerate the data acquisition process. For any given IRT test run, up to five spanwise sections of the ice shape are traced and digitized in this manner. There are several steps within this process that can potentially cause experimental error. Those that can be quantified by the current technique are the spanwise variability, the repeatability error, and errors involved in the tracing technique.

\section{Results and Comparison Methodology}

\section{A. Collection Efficiency Results}

The comparison process for collection efficiency mimics the process used in a previous report (ref. 12) for comparing ice shapes. The following six parameters were chosen to characterize the collection efficiency results: maximum collection efficiency $\left(\beta_{\max }\right)$, total collection efficiency $(E)$ which is proportional to total water catch rate, upper and lower impingement limits $\left(s_{u}\right.$ and $\left.s_{1}\right)$ and the location on the upper and lower surface where collection efficiency reached 10 percent $\left(s_{u 10}\right.$ and $\left.s_{110}\right)$. These parameters are shown on a representative collection efficiency curve in figure 1 below. The parameters are labeled on the figure for both the experimental and numerical results. The example shown is for the GLC305 airfoil at $1^{\circ}$ AOA and $168 \mu \mathrm{m}$ MVD. While this figure depicts the impingement distance based on wrap distance, the impingement limit comparisons were done using the $x$-distance from the leading edge. For the ice shape cases, $x / c=0$ represents the leading edge of the clean airfoil geometry.

The six parameters were chosen as being of interest in designing deicing systems. The maximum collection efficiency and total water catch are critical parameters for evaporative systems. Impingement limits are used extensively for designing the limits of ice protection systems. The 10 percent impingement limits were included in this parameter list since some use this location to define the limits of ice protection. This assumption may be due to the insensitivity of an airfoil to small amounts of ice or based on user assumptions of the software's accuracy. The six parameters were measured for the experimental data and for each of the predicted runs. The values were then compared by absolute value, percent difference and for impingement limits by percent chord difference. Results will be shown for the average comparisons as well as a statistical analysis of the software accuracy.

Comparisons of the six parameters were made between LEWICE and the experimental data. Since the current correlation is based upon the experimental database it is compared against, this report will only show a limited number of results in order to concentrate on the ice shape comparison. Since the splashing and breakup model is not complete, it can be activated or deactivated by the user. Although all effects are modeled, this report will refer to the splashing, breakup, and bouncing model as simply the splashing model since droplet splashing had a much larger effect on the results than droplet breakup. LEWICE was 
run four times for each condition in the database. In the first option, LEWICE was run without splashing effects and using Naviér-Stokes flow solutions from WIND. This option was labeled "NS-NS" (NaviérStokes, no splashing). In the second option, splashing was considered along with the Naviér-Stokes flow solver. This option was labeled "NS-S". The third option used the embedded potential flow solver and ignoring splashing and breakup. This option is labeled "PF-NS" (potential flow, no splashing) in some charts. In the fourth option, LEWICE was run using the potential flow solver and considering splashing. This option is labeled "PF-S". In the third option, the Naviér-Stokes flow solver WIND replaced the potential flow solver. All cases were run with 27 bin drop size distributions as measured in the experiment.

1. Total Mass Flux

The total mass flux was obtained by integrating the collection efficiency values with respect to the wrap distance, $\dot{m}=\frac{L W C^{*} V}{c} * \int \beta d s$. Percentage differences were calculated and tabulated with the other results. Statistical averages were also measured for this variable. Figure 2 shows the prediction of mass flux for the four LEWICE scenarios. The solid bars show the average difference between the prediction and experiment while the vertical error bars show the variability (standard deviation) of the results.

This figure best demonstrates the improvement achieved by using the splashing model. Changing the flow solver to Naviér-Stokes had only a small effect on water catch while there is a significant overprediction of water catch if splashing is not included. The current splashing model corrects the problem shown previously of removing too much mass in the lowest drop size range. The model shows a consistent improvement for SLD drop sizes of nearly four-fold improvement in accuracy for water mass flux (from a difference of 60 or 80 to a 20 percent difference). The average difference in the SLD range is now comparable to the accuracy for the appendix C cases. Since the current correlation is based upon the same data set that it is compared against, a good comparison is assured for all drop sizes. During the calibration process, correlations were found that had a lower average error for the parameters selected, but the amount of under prediction was deemed too great. It was desired to have a correlation that was slightly conservative when an exact match to the experimental data could not be found. The next section will show how this calibrated model performs against the ice shape database.

\section{B. Ice Shape Results}

This section describes the methodology used to make the quantitative measurements on experimental and predicted ice shapes. This methodology has been incorporated into a software utility called THICK that calculates and outputs the parameters described. This software was created in order to process the large number of ice shapes presented in this report. This program reads two geometry files: one for the clean airfoil and one containing an ice shape. This utility has been documented in the LEWICE 3.0 User Manual (ref. 2). This software has recently been revised to more accurately capture ice features of interest. In particular, ice shapes are first segregated into the following categories: roughness shapes (low exposure times), rime shapes, mixed shapes $\left(0.6<N_{f}<1\right)$, and glaze $\left(N_{f}<0.6\right)$. Roughness shapes use icing limit for comparison. Rime shapes use area, maximum thickness, and icing limit. The glaze and mixed shapes are categorized using icing limit, area, horn height, horn thickness, and leading edge thickness. The parameters were defined in the previous validation report, although area is now defined as the true area rather than the integrated thickness. The parameters are diagrammed in the figure below.

A total of 3049 LEWICE cases were performed in this validation effort. There were 1626 unique cases with one spray condition and 59 for cases with multiple spray conditions. The 944 appendix C cases were all run with a monodispersed drop size. The 682 SLD cases were run three times. The first set used a monodispersed drop size equal to the MVD. The second set of SLD runs used a 27 bin drop size distribution. Since drop size distributions in the tunnel are only known at calibration points, the drop size distributions for these runs were estimated from the known distributions. The normalized distribution used for these runs is shown in figure 4. This normalized distribution is then multiplied by the MVD to obtain the droplet distribution used for the LEWICE runs. The last set of runs used the 27 bin drop size 
distributions with the splashing effects turned on. Since splashing effects depend so greatly on the drop size, it was not considered appropriate to use the splashing effects with a monodispersed drop size.

Due to the large number of cases, results were obtained using automated scripts. For the LEWICE cases, runs were produced using a utility program called LewCon. This program was created for this validation effort. It was written by Aaron Armstrong from Brigham Young University at Idaho and later modified by this author. The utility is included with the latest LEWICE release. The program loads conditions from an Excel spreadsheet and uses those values to create the LEWICE input files. The program also runs LEWICE and places the results, including charts, into individual Excel files for each case run. The experimental data was added to these charts using several Excel macros developed by this author and by Timothy Mosig from the Worchester Polytechnic Institute. The Excel macros also ran the THICK utility on the LEWICE shapes and the experimental ice shapes to generate the ice shape measurements presented in this report. The following sections will describe the results of that process by showing comparisons of different ice shapes with LEWICE.

\section{Icing Limits}

The icing limits are the chordwise locations on the ice shape on the upper and lower surface where the ice shape merges with the airfoil. Both the wrap distance from the leading edge and the $x$-distance are recorded for each icing limit. The results presented here are for the wrap distance values.

Figure 5 shows the results of these measurements for both the experimental ice shapes and for LEWICE. In this comparison, each measurement on an experimental shape is compared against the average measurement for that condition. It does not matter whether the experimental shape is a repeat run or a tracing at a different location since the previous validation report showed that the variation is very similar. The LEWICE comparison is the difference between the measurement on the LEWICE shape and the experimental average value. If only one experimental ice shape was available for a given condition, the measurement on that experimental ice shape was taken as the average value for the condition and compared to LEWICE. These results are presented as a percentage of chord in order to normalize the results for different cases. This figure shows that the experimental variation in the lower icing limit is 2 percent of chord while the LEWICE result lies within 4.5 percent of chord from the experimental average value. This result uses the absolute error for each case in order to compute the average and represents an improvement over the previous validation effort. Contrary to popular belief, in the majority of cases LEWICE underpredicts rather than overpredicts the icing limit as compared to the experimental data. This result can likely be attributed to the use of a monodispersed drop size when obtaining the predicted result. Additionally, there were no discernable trends in the data due to ice type (rime, mixed, glaze). Figure 6 shows the comparison just for the SLD database. Use of a droplet distribution, while physically more accurate, makes the agreement with experiment slightly worse.

\section{Maximum Ice Thickness (Horns)}

The current release of the THICK utility has an improved methodology for finding the glaze ice horns. The routine first calculates the ice thickness normal to the surface at each location. Then the program finds the "convex hull" of the ice shape and selects the two largest thicknesses on the convex hull as the ice horns. The convex hull are those points on a geometry that create a convex surface. In order to compare different conditions with different chord lengths and accretion conditions, the individual ice thicknesses were non-dimensionalized by the maximum accumulation thickness as given in the equation below.

$$
t_{\max }=\frac{(L W C)(V)(\text { Time })}{\rho_{\text {ice }}}
$$

Figure 7 shows the dimensionless difference in ice thickness for the three ice thickness measurements made in this report. The previous validation showed that repeatability differences and spanwise variations 
were on the same magnitude, so they were not plotted separately in this report. This figure shows that the max. thicknesses can be measured to within 18 percent experimentally and that the average difference for the LEWICE cases is

20 percent for max. thickness. Both the experimental variation and the LEWICE predicted values show a higher difference for horn height than those reported in the previous validation effort. This occurred solely due to errors in the current automated procedure. The large error bars for the mixed ice shape comparison are an indication of this effect. The utility program THICK does not always extract the correct location for the ice horns. However, in order to correct this result and present a proper comparison would require manual assessment of each horn selection. This process could not be completed in time for this report. Figure 8 shows the comparison for just the SLD data. Once again although the use of a droplet distribution and a splashing model are considered more physically accurate, that does not necessarily translate to actual comparisons.

\section{E. Ice Area}

The iced area is calculated by finding the area of the iced surface through integration, then subtracting the area of the clean airfoil. A unified comparison of ice area for cases with different absolute areas also poses a problem. In this report, the area difference has been nondimensionalized by the maximum accumulation thickness given earlier and by the airfoil thickness. It should be noted that the absolute values for ice area are maintained in the Microsoft ${ }^{\circledR}$ Excel (Redmond, WA) spreadsheet so that the users of this data can make their own comparisons.

Figure 9 shows the results for the ice area comparison for all cases and for SLD conditions. This figure shows that the experimental difference in ice area is less than 10 percent while for the LEWICE results the variation is approximately 16 percent. Once again there are no discernable trends in the comparison based on ice type.

\section{F. Angle at Max. Thickness (Horn Angle)}

The horn angle was defined as the angle between two line segments. The first line segment is a horizontal line which goes through the leading edge of the airfoil (minimum $x$-location at $\mathrm{AOA}=0^{\circ}$ ). The second line segment is defined by the leading edge of the clean airfoil and the ice horn location. This angle was measured for all ice shapes whether or not they fit the classical definition of having a glaze ice horn. Because of this, the ice shapes were first separated into four categories: roughness, rime, mixed, and glaze shapes. The separation of the data into different categoriesallows for a truer comparison of results.

Figure 10 shows the variation in max. thickness angle for LEWICE and for the experimental categories described earlier. Results are presented in degrees. This figure shows that the variation in the experimental data is $26^{\circ}$ for the upper angle, and $31^{\circ}$ for the lower angle. The LEWICE difference from the experimental average are essentially the same as the experimental variation. Once again, however, this variation is primarily due to errors in the automated process and not due to actual differences in shapes. Qualitative assessment indicates that the relative comparison is accurate. That is, the difference in prediction from LEWICE to the experimental average is on the same order as the variability in the data itself. Figure 11 shows the comparison with just the SLD data. Similar to the other measurements, the LEWICE SLD results are slightly better than the overall comparison and is made slightly worse by introducing a distribution with splashing. This could also indicate that the splashing model could be better calibrated for ice shapes as well as for water impingement. However due to the large number of ice shape, this was not practical.

\section{G. Overall Assessment}

Once the individual measurements are taken for each ice shape, it becomes useful to create an overall assessment of the ice shape prediction. Since each measurement is different, several methods could be used to assess the overall difference between two ice shapes. Eight of the 10 measured values presented in this report have been nondimensionalized. Angles do not have a characteristic measure to use for nondimensionalization, so the three angle criteria are reported in degrees. The overall assessment was 
determined by an average of the eight individual dimensionless values and the three angle criteria in degrees.

Figure 12 shows the comparison of the overall assessment for the experimental variability and for LEWICE. This calculation shows an average overall difference of approximately 12 percent for the experimental data base and 14 percent for LEWICE. The standard deviation is 16 percent for both the experimental data and for the LEWICE results. In order to determine if this simple average is a good assessment of the variation, plots were made of the average variation for the experimental shapes and for the LEWICE shapes.

Figure 13 shows an example of two ice shapes which are near the overall experimental average. This plot shows the spanwise variability from a data point in the LTHS database. The qualitative comparison of these two ice shapes suggests that the overall assessment parameter is a reasonable approximation. The comparison also shows the problem with automatically generating ice measurement parameters. Although the two shapes are very simliar, THICK chooses locations for both the upper and lower horn for these shapes that are very different which affects the quantitative analysis. Similarly, figure 14 shows an example which is at the average variation for the LEWICE cases. The qualitative assessment of this comparison also agrees with the overall assessment parameter used.

\section{Conclusions}

A review of the physical effects of large droplet phenomena confirmed that droplet splashing is the primary physics that is not modeled in icing software in this drop size regime. Empirical models for these phenomena were presented. The resulting effects of the additional physics on water collection in LEWICE were presented.

The results show that the empirical splashing models in the open literature only accounted for splashing effects near the leading edge. The models, all of which are based on the velocity component normal to the surface, could not explain the measured decrease in water collection near the impingement limits. Additionally, it was necessary to extrapolate values from that empirical data for this effort. It is hypothesized that droplets that impact at high total velocities $(>30 \mathrm{~m} / \mathrm{s})$ but low impact angles $\left(<20^{\circ}\right)$ may rebound in a manner different than the current experimental data at the lower velocities. A new model based on physical arguments was proposed to account for the additional physical phenomena that occur in the SLD regime.

The model was calibrated against a database of collection efficiencies. A comprehensive comparison was performed that compared maximum collection efficiency, total water mass flux, upper and lower impingement limits, and upper and lower 10 percent limits. Comparisons were made with and without the new model to demonstrate its effectiveness. Comparisons were also made to assess the effect of using a Naviér-Stokes flow solver and to assess the effect of other adjustments including the use of 27-bin drop size distributions instead of 10-bin distributions.

The accuracy of the model was demonstrated against a voluminous database of ice shapes measured in the IRT. Over 3000 experimental ice shapes were used in this comparison. Ice shape measurements were made for upper and lower icing limit, upper and lower horn height, leading edge minimum thickness, area and upper and lower horn angle. Due to the large number of cases, ice shape generation and comparison were performed using several scripts which limited the amount of time that could be spent manually evaluating the comparisons. The measurements showed that LEWICE predictions compared to the experimental averages were on the same level of accuracy as the tunnel variability for all parameters, even in the SLD regime. The overall comparison showed the LEWICE results at 16 percent with a standard deviation of 16 percent while the experimental variation was 16 percent with a standard deviation of 16 percent. 


\section{References}

1. "In-flight Icing Encounter and Loss of Control Simmons Airlines, d.b.a. American Eagle Flight 4184 Avions de Transport Regional (ATR) Model 72-212, N401AM, Roselawn, IN, Oct. 31, 1994," NTSB Report Number: AAR-96-01.

2. G.A. Isaac, S.G. Cober, J.W. Strapp, D. Hudak, T.P. Ratvasky, D.L. Marcotte, and F. Fabry, "Preliminary Results from the Alliance Research Study (AIRS)," AIAA-2001-393, Jan. 2001.

3. M. Potapczuk, "Ice Mass Measurements: Implications for the Ice Accretion Process," AIAA-2003387, Jan. 2003.

4. T. Bond, M. Potapczuk and D. Miller, "Overview of SLD Engineering Tool Development," AIAA2003-386, Jan. 2003.

5. Gent, J. Ford and R. Moser, D. Miller, "Results from SLD Mass Loss Tests in the ACT Luton Icing Research Wind Tunnel,” AIAA-2003-389, Jan. 6-9, 2003.

6. Tan, S.C. and Papadakis, M., " General Effects of Large Droplet Dynamics on Ice Accretion Modeling,” AIAA-2003-392, Jan. 2003.

7. Rutkowski, A., Wright, W.B. and Potapczuk, M. G., "Numerical Study of Droplet Splashing and ReImpingement," AIAA-2003-388, Jan. 2003.

8. W. Wright, M. Potapczuk, "Empirical Modeling of SLD Physics," AIAA-2004-412, Jan. 2004.

9. Papadakis, M., Elangonan, R., Freund, Jr., G. A., Breer, M., Zumwalt, G. W. and Whitmer, L., "An Experimental Method for Measuring Water Droplet Impingement Efficiency on Two- and ThreeDimensional Bodies," NASA CR-4257, Nov. 1989.

10. Papadakis, M., Breer, M., Craig, N. and Liu, X., "Experimental Water Droplet Impingement Data on Airfoils, Simulated Ice Shapes, an Engine Inlet and a Finite Wing," NASA CR-4636, DOT/FAA/CT-TN93/18, Dec. 1994.

11. Papadakis, M., Hung, K.E., Vu, G.T., Yeong, H.W., Bidwell, C.S., Breer, M.D., Bencic, T.J., "Experimental Investigation of Water Droplet Impingement on Airfoils, Finite Wings, and an S-Duct Engine Inlet, NASA/TM-2002-211700, Oct. 2002.

12. Wright, W. B. and Rutkowski, A., "Validation Results for LEWICE 2.0," NASA CR-208690, Nov. 1998.

13. Bush, R.H., Power, G.D. and Towne, C.E., "WIND: The Production Flow Solver of the NPARC Alliance," AIAA-98-0935, Jan. 1998.

14. Wright, W.B., "Users Manual for the NASA Glenn Ice Accretion Code LEWICE Version 3.0," available on the NASA LEWICE 3.0 release CD, Apr. 2003.

15. Thompson, D.S. and Soni, B.K., "ICEG2D: A Software Package for Ice Accretion Prediction," AIAA-2003-1070, Jan. 2003

16. Clift, R., Grace, J.R., and Weber, M.E., "Bubbles, Drops, and Particles,” Academic Press, New York, 1978.

17. Tavlarides, L.T., Coulalogou, C.A., Zeitlin, M.A., Klinzing, G.E., Gal-or, B., "Bubble and Drop Phenomena," Ind. And Eng. Chem., vol. 62, no. 11, pp. 6-27, Nov. 1970.

18. Michaelides, E.E., "Review - The Transient Equation of Motion for Particles, Bubbles, and Droplets,” J. Fluids Engr., vol. 119, pp. 233-246, June 1997.

19. Krzeczkowski, S.A., "Measurement of Liquid Droplet Disintegration Mechanism," int. J. Multiphase Flow, vol. 6, pp. 227-239, 1980.

20. Hsiang, L.P. and Faeth. G.M., "Secondary Drop Breakup in the Deformation Regime," AIAA-920110, Jan. 1992.

21. Ibrahim, E.A., Yang, H.Q., and Przekwas, A.J., "Modeling of Spray Droplets Deformation and Breakup,” J. Prop., vol. 9, no. 4, pp. 651-654, 1993.

22. Dai, Z. and Faeth, G.M., "Temporal Properties of Multimode Secondary Droplet Breakup," AIAA 99-0333, Jan. 1999. 
23. Stow, C.D., and Hadfield, M.G., "An Experimental Investigation of Fluid Flow Resulting from the Impact of a Water Drop with an Unyielding Dry Surface,” Proc. R. soc. Lond. A vol. 373, pp. 419-441, 1981.

24. Macklin, W.C. and Metaxas, G.J., "Splashing of Drops on Liquid Layers," J. App. Phys., vol. 47, no. 9, pp. 3963-3970, Sept. 1976.

25. Jayarante, O.W. and Mason, B.J., "The Coalescence and Bouncing of Water Drops at an Air/Water Interface," proc. Roy. Sci. A., vol. 280, pp. 545-565, 1965.

26. Wright, A.C., "A Physically-Based Model of the Dispersion of Splash Droplets Ejected from a Water Drop Impact," Earth Surf. Proc. And Landforms, vol. 11, pp. 351-367, 1986.

27. Harlow F.H. and Shannon, J.P., "The Splash of a Liquid Drop,” J. App. Phys., vol. 38, no. 10, pp. 3855-3866, 1967.

28. Yarin. A.L. and Weiss, D.A., "Impact of Drops on Solid Surfaces: Self-Similar Capillary Waves, and Splashing as a New Type of Kinematic Discontinuity," J. Fluid Mech., vol. 283, pp. 141-173, 1995.

29. Weiss D.A., "Periodischer Aufprall monodisperser Tropen gleicher Geschwindigkeit auf feste Oberflächen," Mitteilungeen aus dem Max-Plank-Institut für Stromungsforschung, Gottingen, Nr. 112, 1993.

30. Rein, M., "Phenomena of Liquid Drop Impact on Solid and Liquid Surfaces," Fl. Dyn. Res., vol. 12, pp. 61-93, 1993.

31. Chandra, S. and Avedisian, C.T., "On the Collision of a Droplet with a Solid Surface," Proc. Roy. Soc. Lond. A, vol. 432, pp. 13-41, 1991.

32. Hirt, C.W., Nicholls, B.D., "Volume of Fluid Method for Dynamic Free Boundary," J. Comp. Phys., vol. 39, 1981.

33. Trapaga, G. and Szekely, J., "Mathematical Modeling of the Isothermal Impingement of Liquid Drops in the Spraying Process," Metallurgical Transactions B, vol. 22B, pp. 901-914, Dec. 1991.

34. Mundo, C., Sommerfeld, M., and Tropea, C., "Droplet-Wall Collisions: Experimental Studies of the Deformation and Breakup Process," Int. J. Multiphase Flow, vol. 21, no. 2, pp. 151-173, 1995.

35. Mundo, C., Tropea, C. and Sommerfeld, M., "Numerical and Experimental Investigation of Spray Characteristics in the Vicinity of a Rigid Wall," Exp. Thermal and Fl. Sci., vol. 15, pp. 228-237, 1997.

36. Mundo, C., Sommerfeld, M., and Tropea, C., "On the Modeling of Liquid Sprays Impinging on Surfaces," Atomization and Sprays, vol. 8, pp. 625-652, 1998.

37. Feo, A., Personal Communication, Dec. 2003.

38. Trujillo, M.F., Matthews, W.S., Lee, C.F., and Peters, J.E., "Modeling and Experiment of Impingement and Atomization of a Liquid Spray on a Wall," Int. J. Engine Research, vol. 1, no. 1, pp. 87-104, 2000.

39. Papadakis, M., Personal Communication, Apr. 2004.

40. D. Anderson and J. Tsao, "Additional Results of Ice-Accretion Scaling at SLD Conditions," AIAA-2003-390, Jan. 6-9, 2003. 


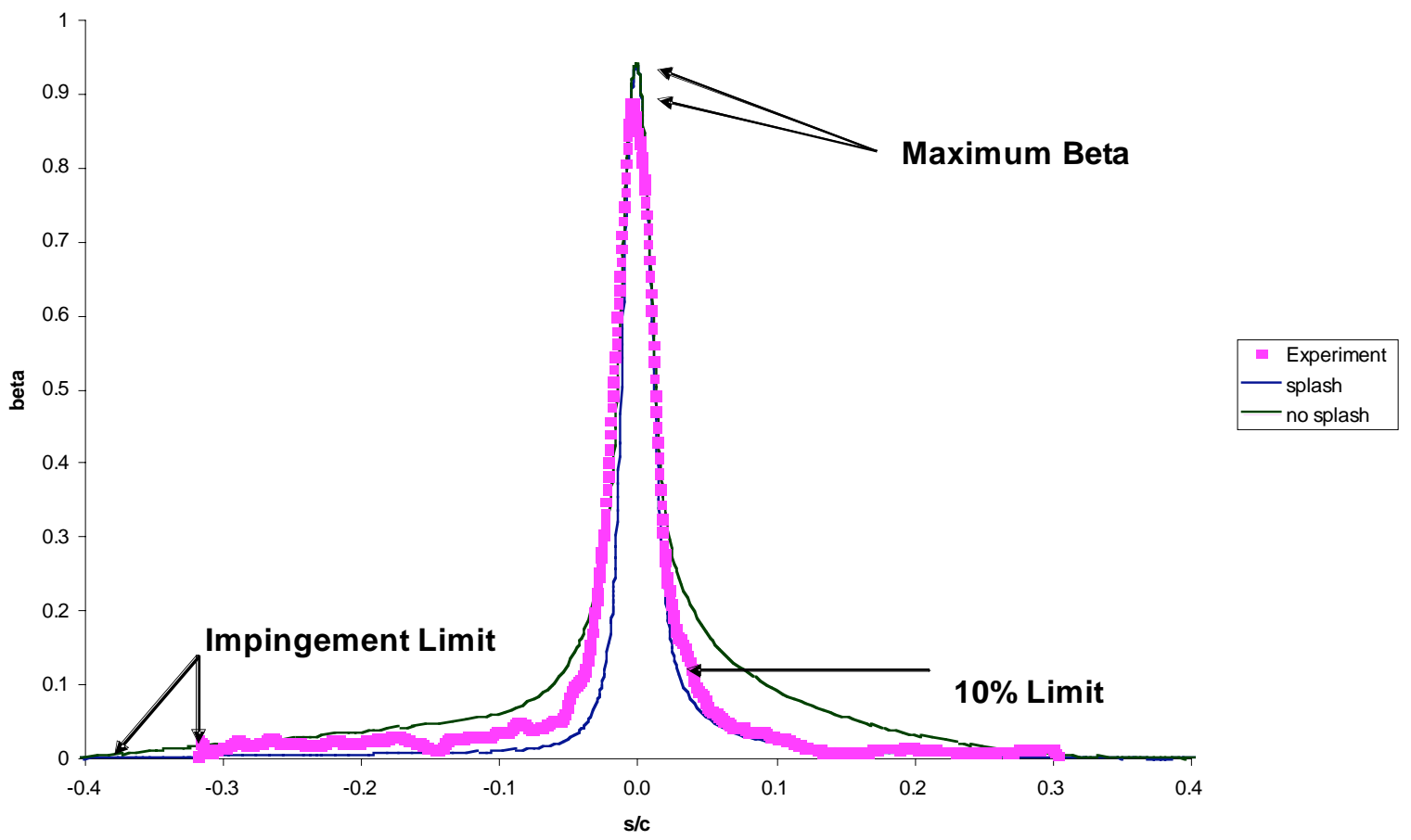

Figure 1.-Sample collection efficiency curve.

Total Water Catch

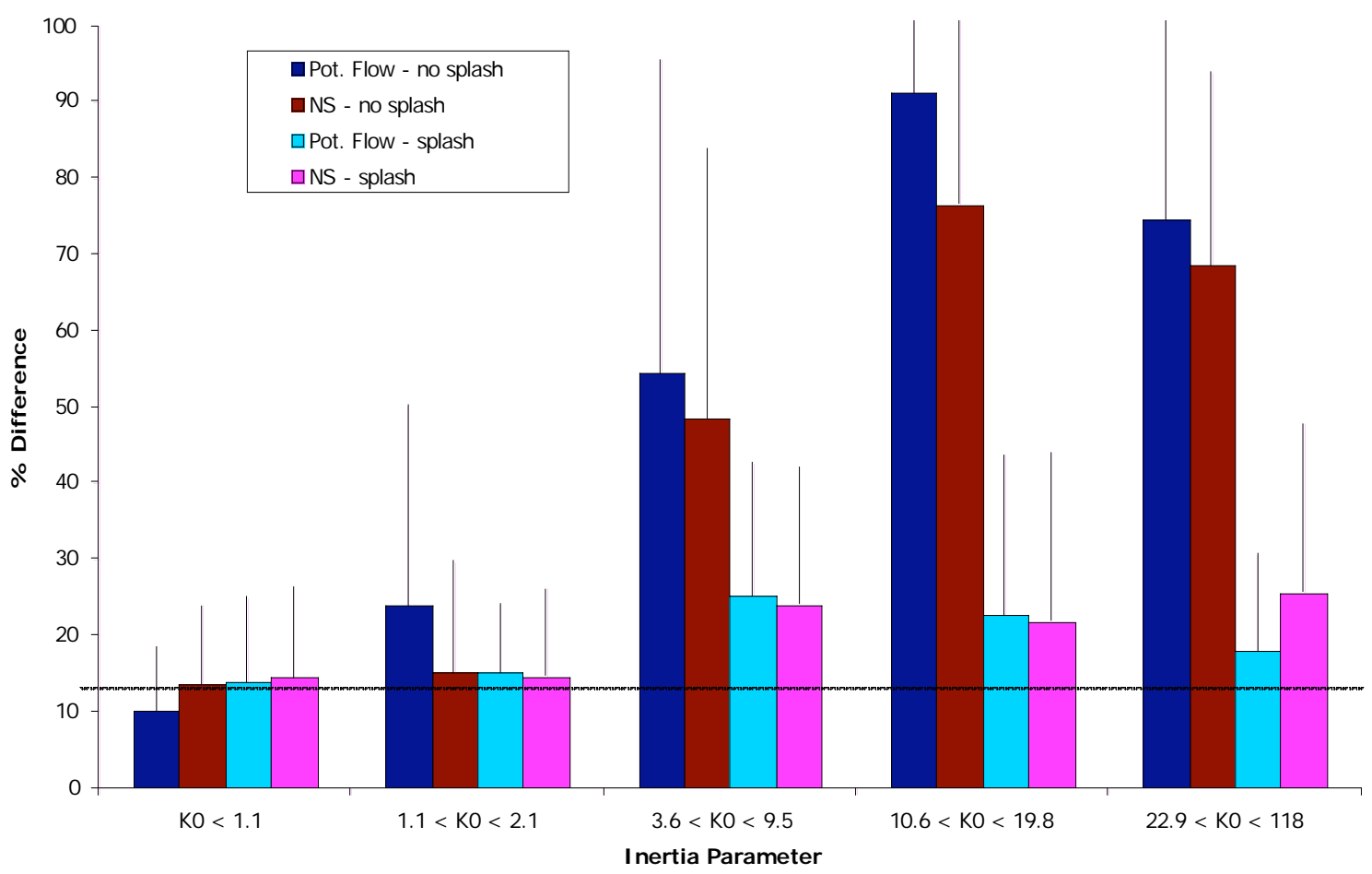

Figure 2.-Comparison of total mass flux. 


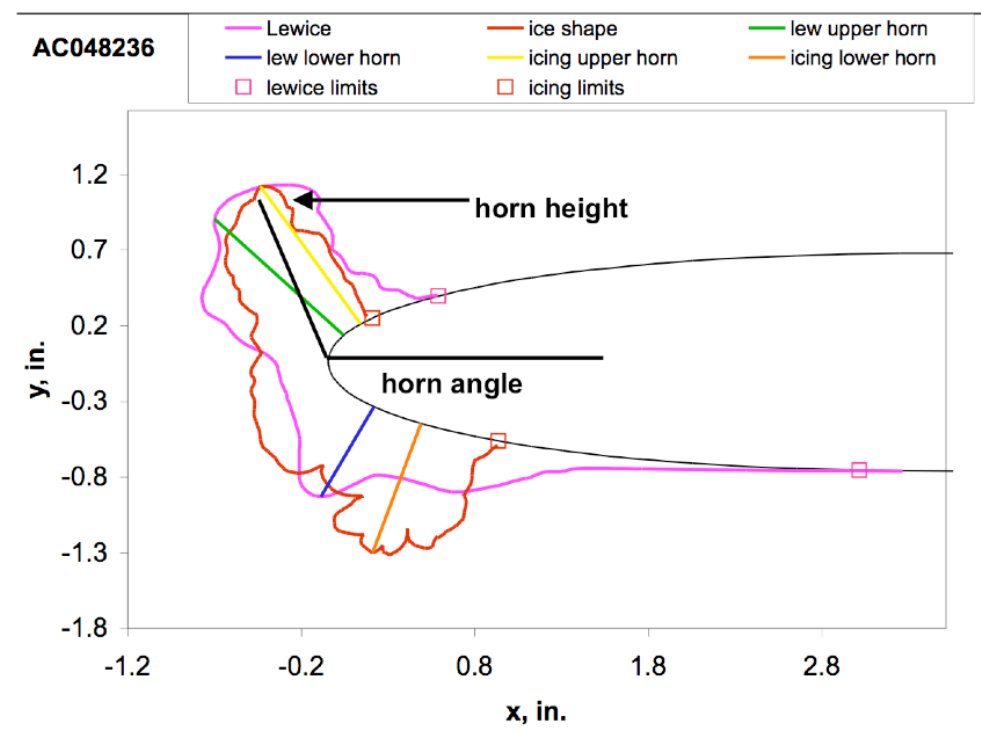

Figure 3.-Ice shape measurements.

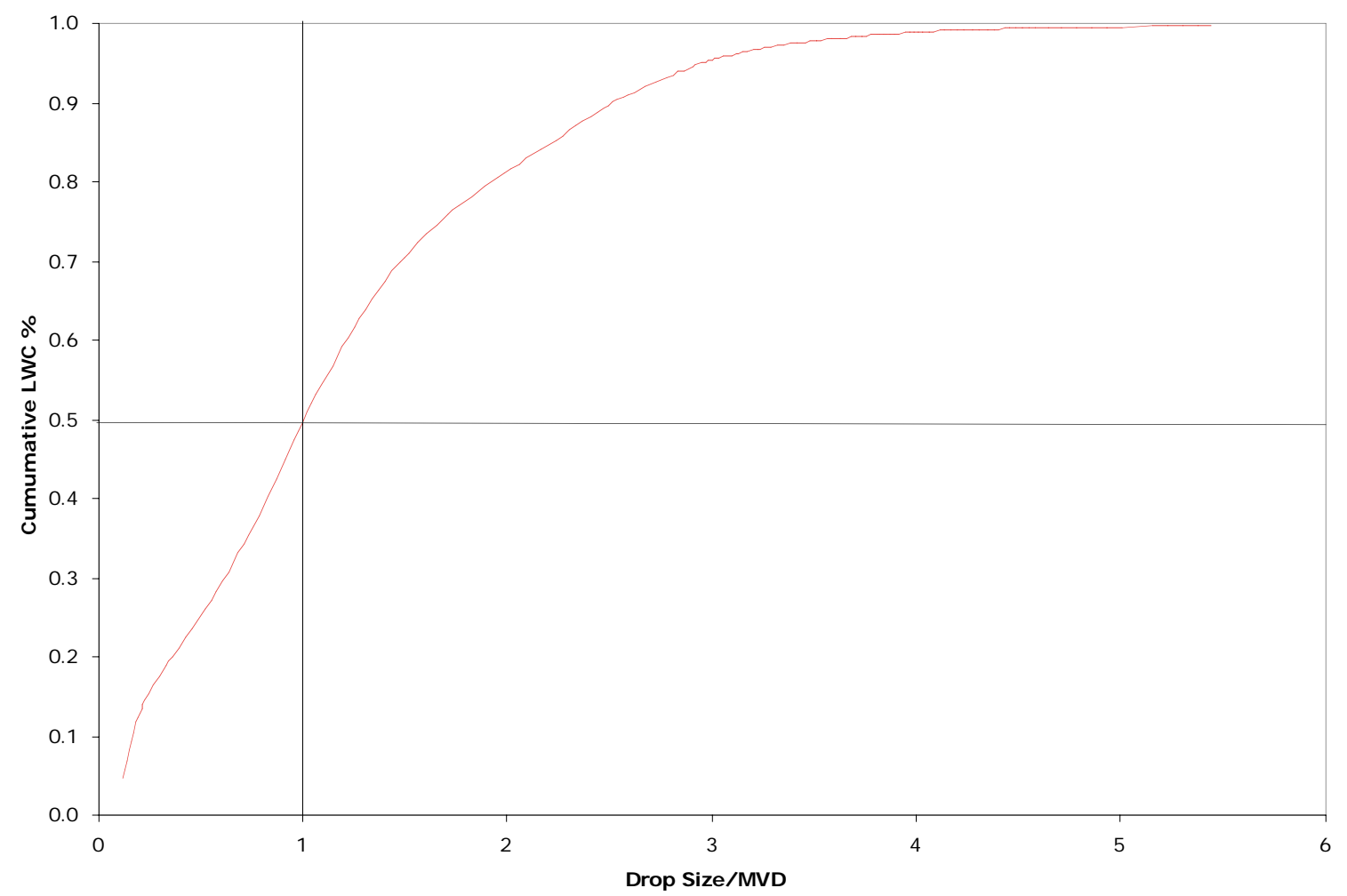

Figure 4.-Drop size distribution for SLD cases. 
Icing Limit

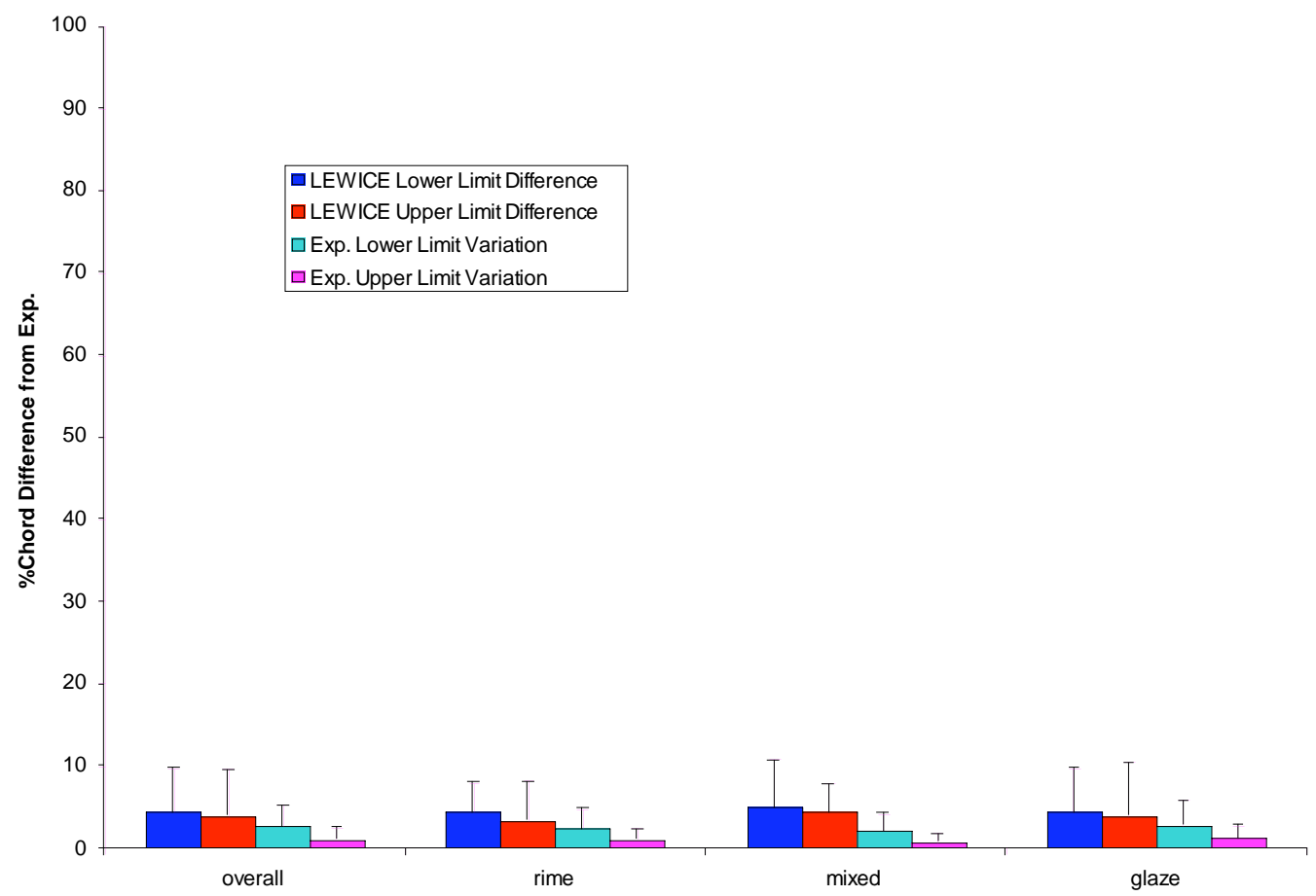

Figure 5.-Icing limit comparison.

SLD Icing Limit

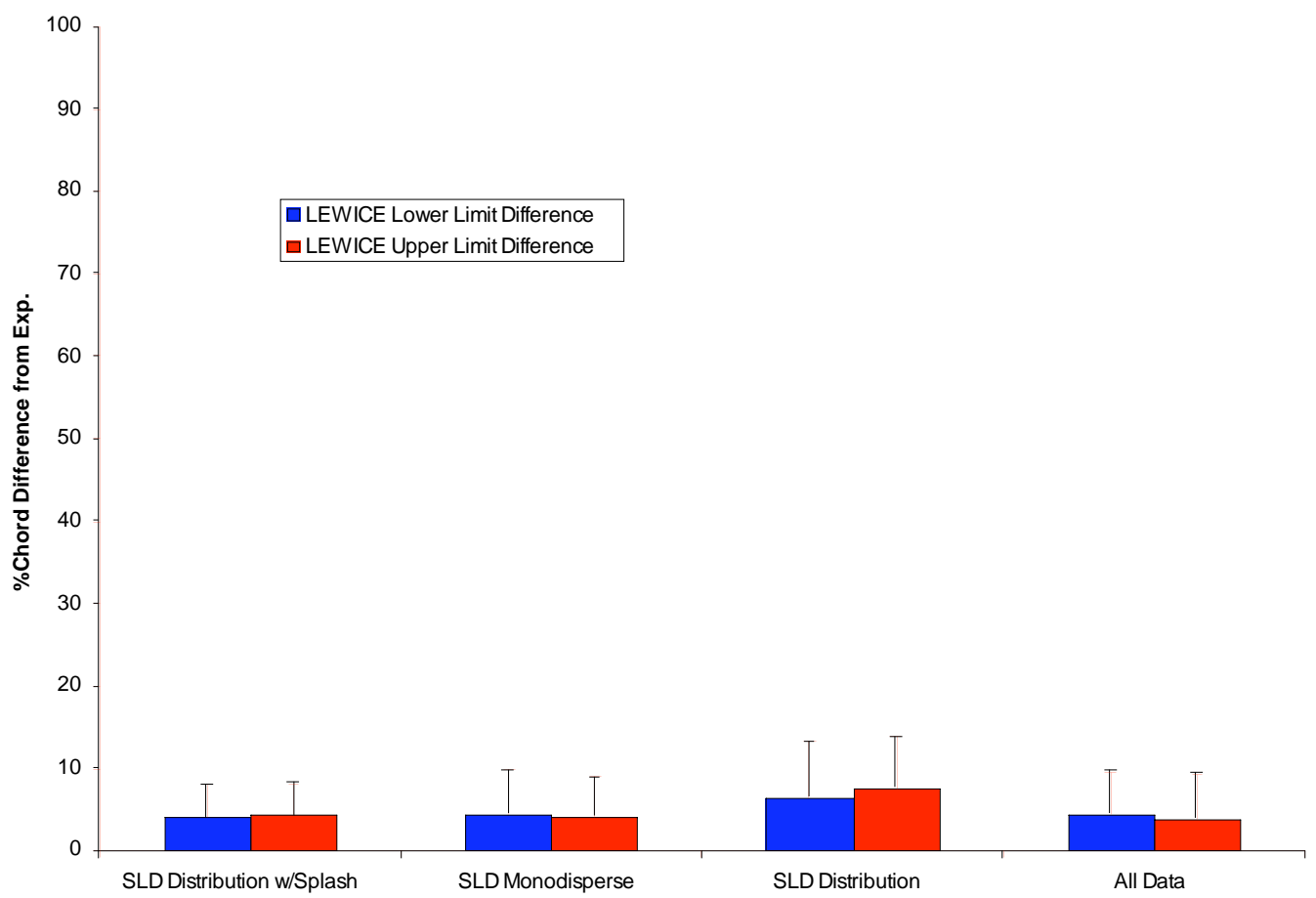

Figure 6.-SLD icing limit comparison. 


\section{Horn Height}



Figure 7.--Horn height comparison.

SLD Horn Height

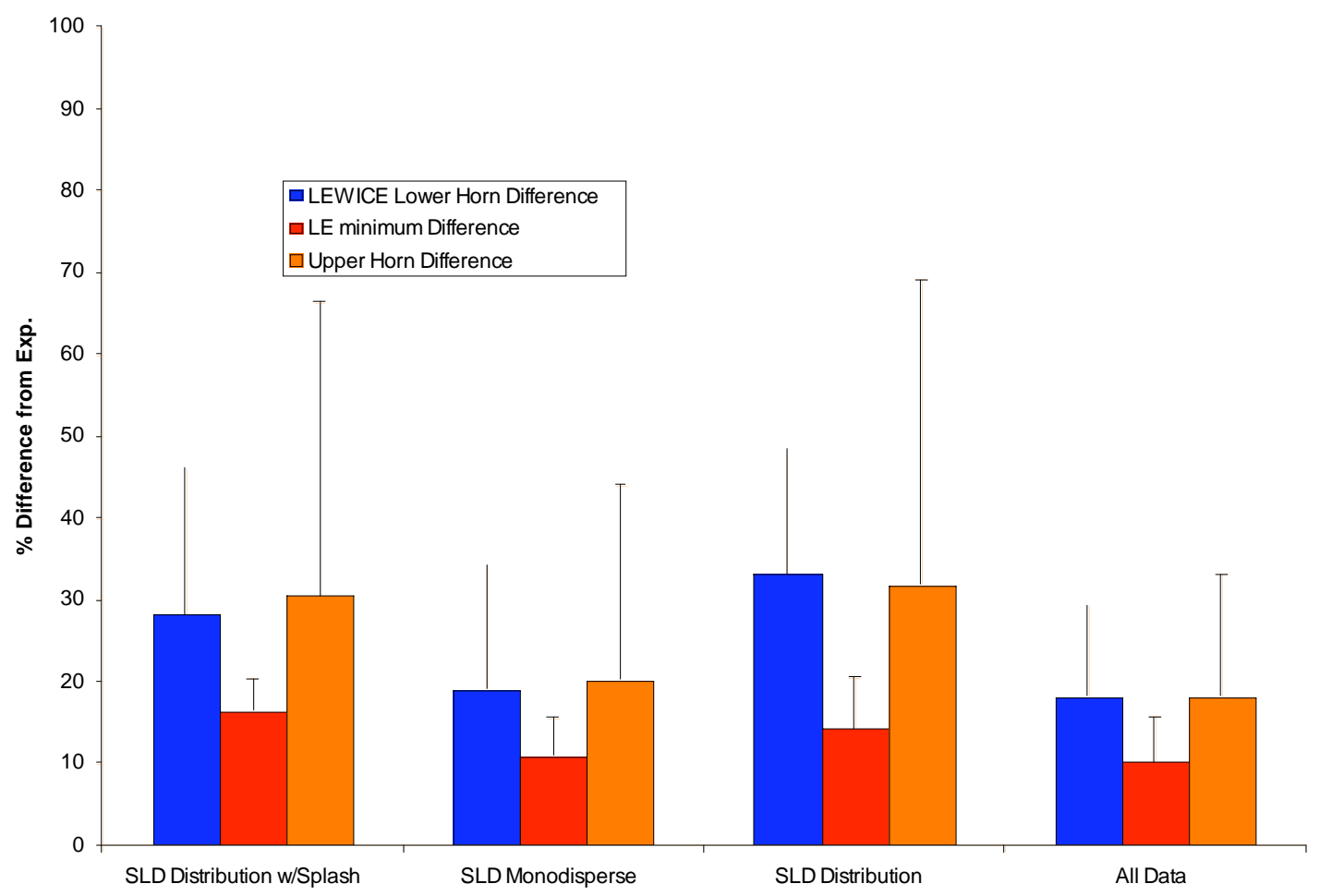

Figure 8.-SLD horn height comparison. 
Ice Area

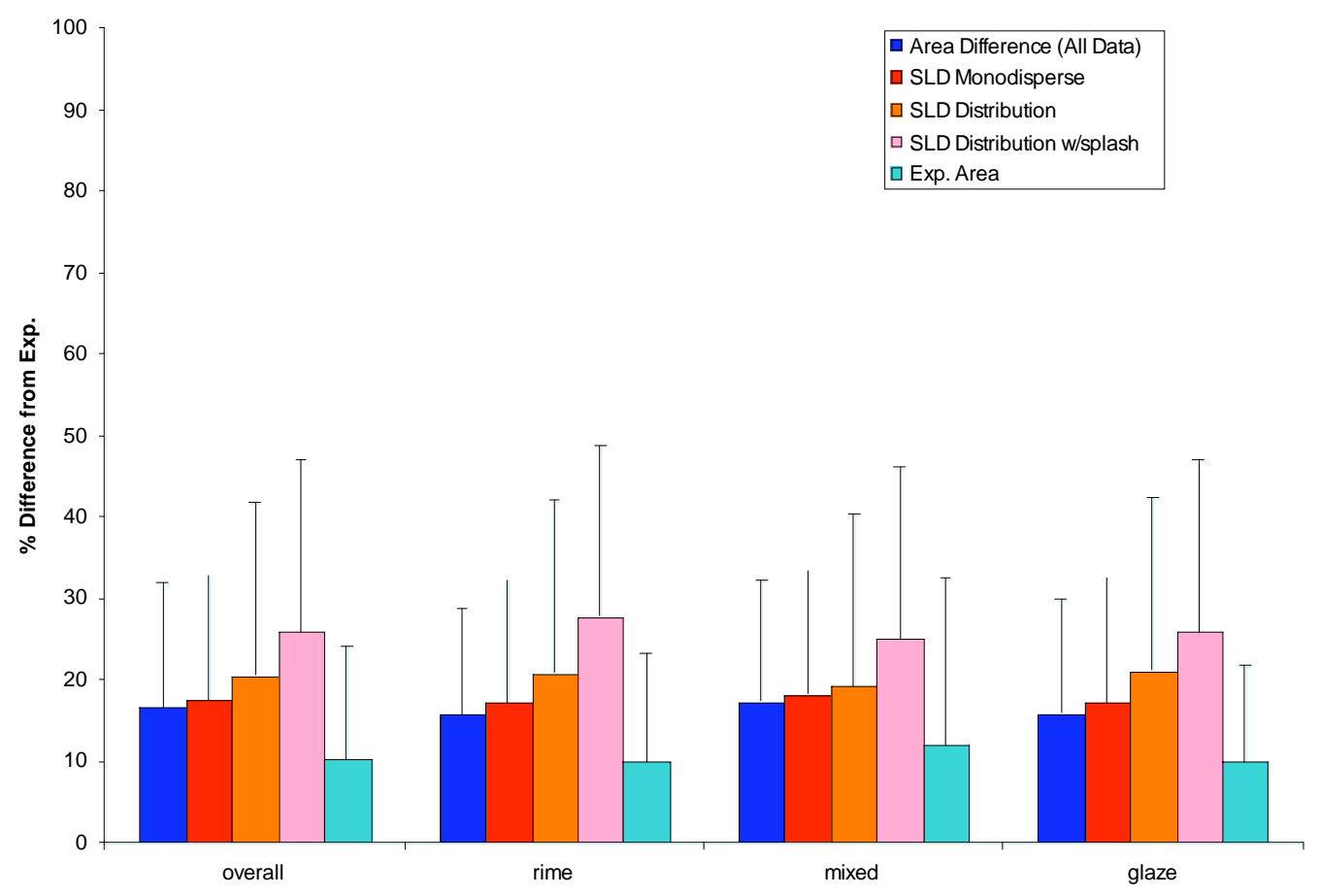

Figure 9.-Ice area comparisons.



Figure 10.- Horn angle comparisons. 
SLD Horn Angle

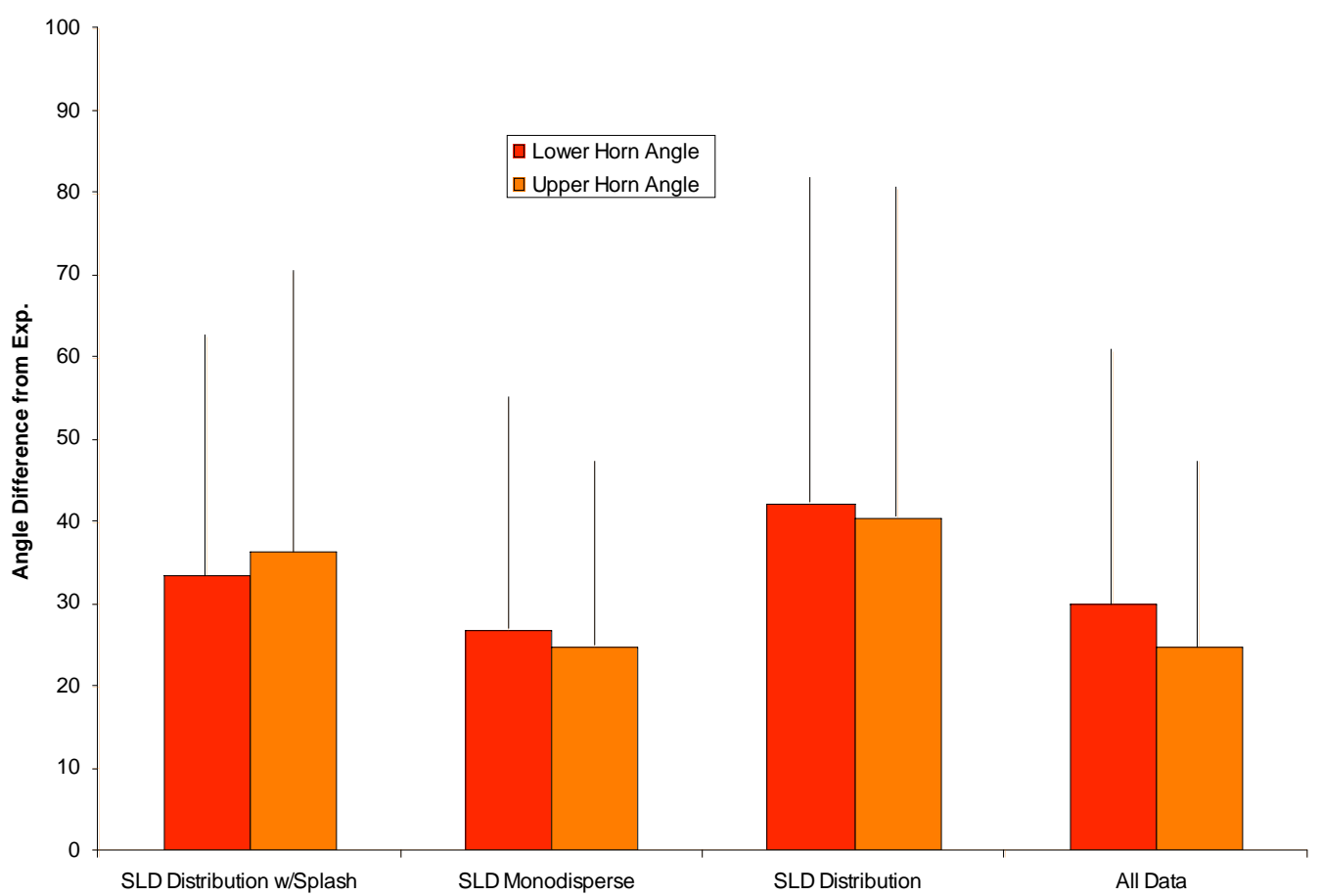

Figure 11.-SLD horn angle comparison.

Parameter Averages

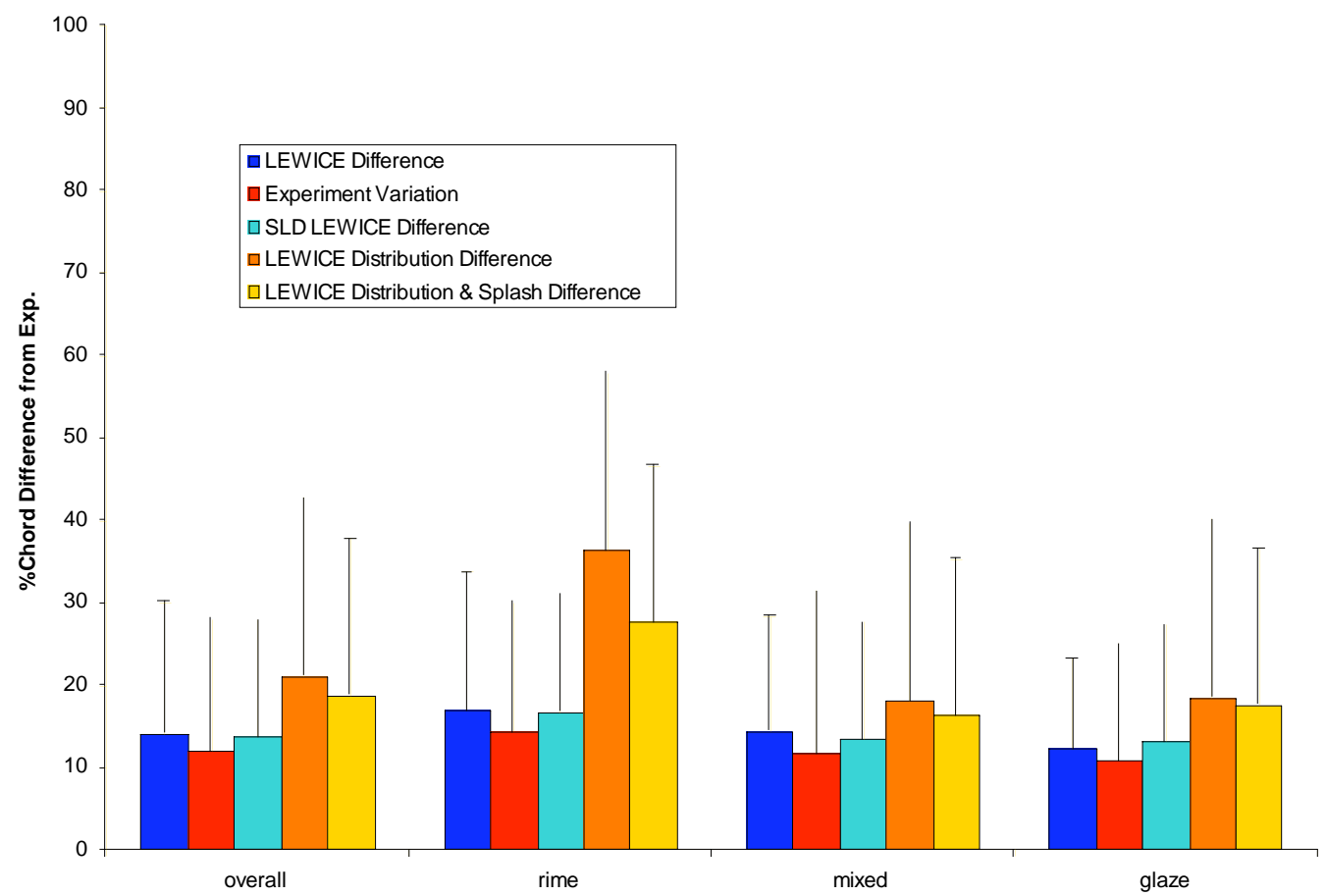

Figure 12.—Overall assessment. 


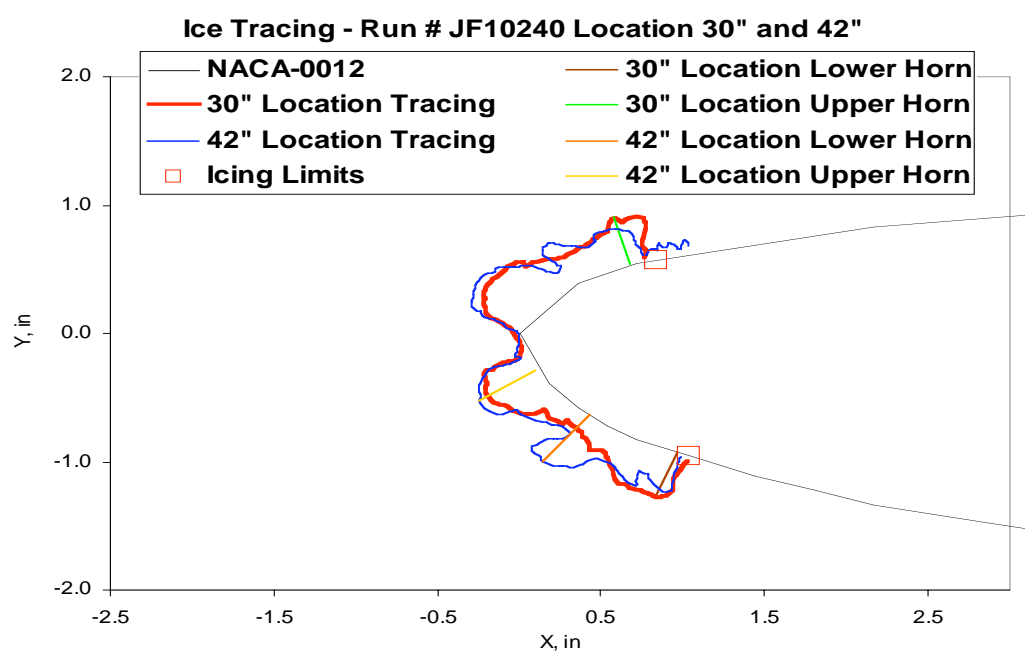

Figure 13.- Average experimental variation.

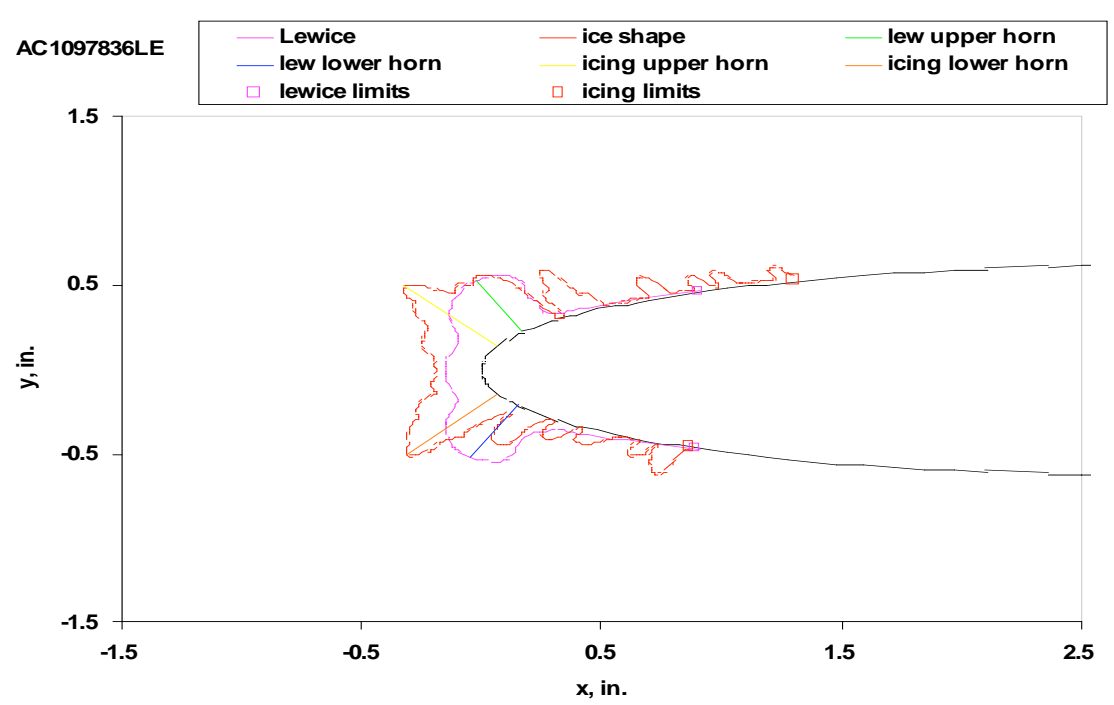

Figure 14.-Average LEWICE variation. 
Public reporting burden for this collection of information is estimated to average 1 hour per response, including the time for reviewing instructions, searching existing data sources, gathering and maintaining the data needed, and completing and reviewing the collection of information. Send comments regarding this burden estimate or any other aspect of this collection of information, including suggestions for reducing this burden, to Washington Headquarters Services, Directorate for Information Operations and Reports, 1215 Jefferson Davis Highway, Suite 1204, Arlington, VA 22202-4302, and to the Office of Management and Budget, Paperwork Reduction Project (0704-0188), Washington, DC 20503.

\begin{tabular}{|l|l|l}
\hline 1. AGENCY USE ONLY (Leave blank) & $\begin{array}{c}\text { 2. REPORT DATE } \\
\text { May } 2006\end{array}$ & $\begin{array}{c}\text { 3. REPORT TYPE AND DATES COVERED } \\
\text { Final Contractor Report }\end{array}$ \\
\hline
\end{tabular}

\section{TITLE AND SUBTITLE}

Further Refinement of the LEWICE SLD Model
5. FUNDING NUMBERS

WBS-457280.02.07.03.02

$$
\text { NAS3-00145 }
$$

William B. Wright

7. PERFORMING ORGANIZATION NAME(S) AND ADDRESS(ES)

8. PERFORMING ORGANIZATION REPORT NUMBER

QSS Group, Inc.

21000 Brookpark Road

Cleveland, Ohio 44135

E-15466

9. SPONSORING/MONITORING AGENCY NAME(S) AND ADDRESS(ES)

National Aeronautics and Space Administration

Washington, DC 20546-0001

10. SPONSORING/MONITORING AGENCY REPORT NUMBER

NASA CR-2006-214132

AIAA-2006-0464

\section{SUPPLEMENTARY NOTES}

Prepared for the 44th Aerospace Sciences Meeting and Exhibit sponsored by the American Institute of Aeronautics and Astronautics, Reno, Nevada, January 9-12, 2006. Project manager, Thomas H. Bond, NASA Glenn Research Center, organization code RTI, 216-433-3900.

12a. DISTRIBUTION/AVAILABILITY STATEMENT

12b. DISTRIBUTION CODE

Unclassified - Unlimited

Subject Categories: 02 and 03

Available electronically at http://gltrs.grc.nasa.gov

This publication is available from the NASA Center for AeroSpace Information, 301-621-0390.

13. ABSTRACT (Maximum 200 words)

A research project is underway at NASA Glenn Research Center to produce computer software that can accurately predict ice growth for any meteorological conditions for any aircraft surface. This report will present results from version 3.2 of this software, which is called LEWICE. This version differs from previous releases in that it incorporates additional thermal analysis capabilities, a pneumatic boot model, interfaces to external computational fluid dynamics (CFD) flow solvers and has an empirical model for the supercooled large droplet (SLD) regime. An extensive comparison against the database of ice shapes and collection efficiencies that have been generated in the NASA Glenn Icing Research Tunnel (IRT) has also been performed. The complete set of data used for this comparison will eventually be available in a contractor report. This paper will show the differences in collection efficiency and ice shape between LEWICE 3.2 and experimental data. This report will first describe the LEWICE 3.2 SLD model. A semi-empirical approach was used to incorporate first order physical effects of large droplet phenomena into icing software. Comparisons are then made to every two-dimensional case in the water collection database and the ice shape database. Each collection efficiency condition was run using the following four assumptions: 1) potential flow, no splashing; 2) potential flow, with splashing; 3) Naviér-Stokes, no splashing; 4) Naviér-Stokes, with splashing. All cases were run with 21 bin drop size distributions and a lift correction (angle of attack adjustment). Quantitative comparisons are shown for impingement limit, maximum water catch, and total collection efficiency. Due to the large number of ice shape cases, comprehensive comparisons were limited to potential flow cases with and without splashing. Quantitative comparisons are shown for horn height, horn angle, icing limit, area, and leading edge thickness. The results show that the predicted results for both ice shape and water collection are within the accuracy limits of the experimental data for the majority of cases.

\begin{tabular}{|l|l|}
\hline 14. SUBJECT TERMS & 15. NUMBER OF PAGES
\end{tabular}

Ice formation; Drops (liquid); Trajectories 28

\begin{tabular}{|c|c|c|}
\hline $\begin{array}{c}\text { 17. SECURITY CLASSIFICATION } \\
\text { OF REPORT } \\
\text { Unclassified }\end{array}$ & $\begin{array}{c}\text { 18. SECURITY CLASSIFICATION } \\
\text { OF THIS PAGE } \\
\text { Unclassified }\end{array}$ & $\begin{array}{c}\text { 19. SECURITY CLASSIFICATION } \\
\text { OF ABSTRACT } \\
\text { Unclassified }\end{array}$ \\
\hline
\end{tabular}



